\title{
Wegener's granulomatosis: Description of a case with oral manifestation
}

\author{
Rosa $M^{\text {a }}$ Reboll-Ferrer ${ }^{1}$, Enrique Zapater-Latorre ${ }^{1}$, Consuelo Calabuig-Crespo ${ }^{2}$, Jorge Basterra-Alegría \\ ${ }^{1}$ MD, PHD, Otorhinolaryngology, General University Hospital of Valencia and Department of Medicine, Valencia (Spain) \\ ${ }^{2}$ PHD, Pathological anatomy, General University Hospital of Valencia and Department of Medicine, Valencia (Spain)
}

\author{
Correspondence: \\ Calle Barreres, No. 99 \\ Puçol (Valencia) 46530 \\ Spain \\ reboll540@yahoo.es
}

Received: 21/06/2009

Accepted: 20/09/2009

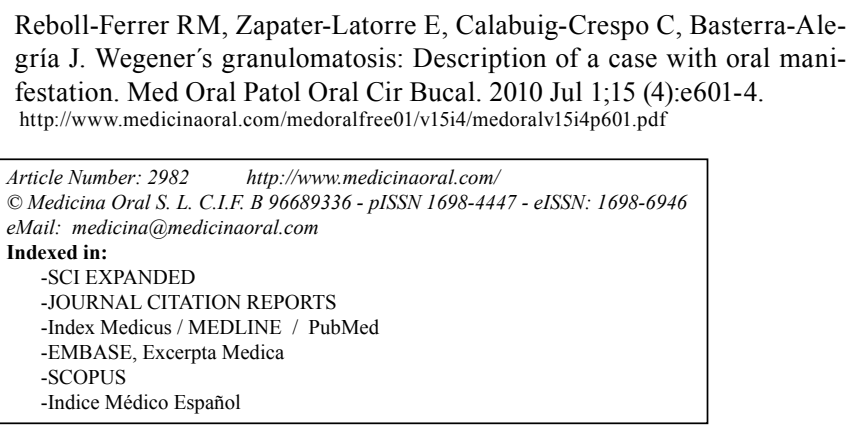

\begin{abstract}
Wegener's granulomatosis is a multisystemic granulomatous vasculitis that predominantly affects the airways and the kidneys, but may affect any organ. Otorhinolaryngological manifestations may be oral ulcers, gingival swelling or septal perforations that can cause saddle nose deformities, rhinitis, sinusitis and hearing loss. The oral ulcers usually occur when the disease is advanced. Renal involvement is characterized by focal and segmental glomerulosclerosis, and determines the evolution. The diagnosis is made by clinical symptoms and signs, the presence of c-ANCA and a positive biopsy. The anatomic pathology is characterized by vasculitis, granulomatous inflammation with multinuclear giant cells and necrosis. The prognosis has improved as a result of treatment with immunosuppressants associated with corticosteroids. We report a case of a 53-year-old patient with Wegener's granulomatosis with oral manifestation, which began as chronic mastitis.
\end{abstract}

Key words: Wegener's granulomatosis, oral ulcer, c-ANCA (Antineutrophil Cytoplasmic Autoantibodies), vasculitis.

\section{Introduction}

Wegener's granulomatosis is a multisystem granulomatous vasculitis that affects the upper and lower airways and kidneys preferentially, but may involve any organ, in fact, each has a broad spectrum of clinical presentations, they can even speak different stages of the disease at the same time at each location, and also can mimic other diseases, which must make a differential diagnosis (1).

The incidence and prevalence of this disease are not exactly clear. There are no significant differences in terms of gender, and the average age of onset of the illness is
41 years old. Different authors report the range of mortality between $9 \%$ and $36 \%$ (2).

Renal involvement is the cause of the majority of the deaths, but its prognosis has improved as a result of introducing immunosuppressive treatment. Its etiology and pathogenesis are unknown, although various theories have been postulated, such as the autoimmune theory, the hypersensitivity theory, and the theory of infection as a precipitating factor of the disease (1).

We report a case of a 53-year-old patient with Wegener's granulomatosis with oral involvement, which began as chronic mastitis. 


\section{Case Report}

We analyze the case of a 53-year-old female patient with an interesting personal history, having presented right chronic mastitis with recurrent breast abscess and having undergone surgical drainage and antibiotic treatment up until about a year ago. The different biopsies performed showed abcessed and necrotic granulation tissue, and one of the biopsies showed steatonecrosis with a giant celular inflammatory reaction and lymphocytic lobulitis. The microbiological study sometimes reported a Staphylococcus aureus infection, whereas others were found to be sterile. Given its very slow evolution, the general surgeons performed a simple mastectomy in May 2008. The anatomic pathological examination showed the presence of a chronic inflammatory infiltrate, with giant-cell reaction and abcessed granulation tissue (Fig. 1). During the period in which the repeated abscesses took place, there were several episodes of skin rash, itching, fever and arthralgia in the lower limbs, which were found to be related to taking antibiotics, especially vancomycin.
The tenth postoperative day of the mastectomy presented lateral odynophagia on the left and hearing loss in the left ear. The otorrynolaryngological exploration revealed a bilateral tympanic retraction without fluid levels, and a hypertrophy of adenoid vegetations in the nasopharynx. The most striking finding was a $4 \mathrm{~cm}$ soft hemipalate ulcer on the left, which had spread to the left anterior tonsillar pillar, and was painful to the touch, with a white background and erythematous borders (Fig. 2a). Biopsies were taken from both the adenoid tissue and the palatine ulcer. The first showed a follicular lymphoid hyperplasia, and it was not possible to process the biopsy of the palate. The cultivation of the palatine exudate showed the presence of candida albicans. The treatment that was prescribed was a masterful formula comprised of nystatin $100000 \mathrm{IU} / \mathrm{cc}, 10 \mathrm{~mL}$ lidocaine $2 \%$ and 1 ampoule of dexamethasone $4 \mathrm{mg}$.

Within fifteen days of the mastectomy, there were arthralgias in the knees and ankles, which were swollen and presented some erythematous-violaceous macules at the pretibial level and lower front of the left foot (Fig.

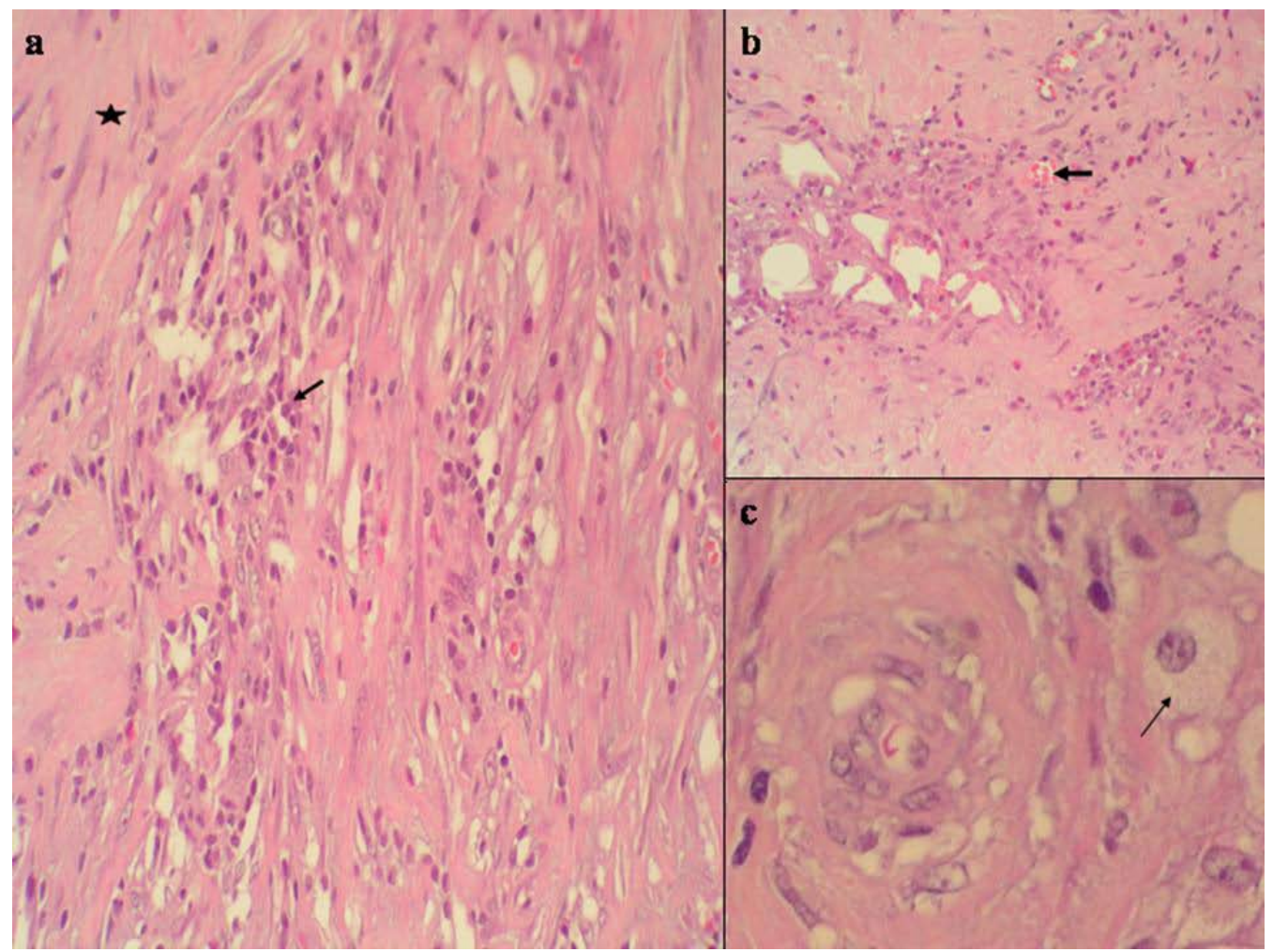

Fig. 1. a. The image shows an advanced stage of vasculitis with poor delineation of the vascular spaces, which have become stenotic or occluded, observing only some spaces with red blood cells in their interior (arrow). Note the increased perivascular collagen with minimal lymphoid component (asterisk), and presence of isolated neutrophils and histiocyte cells, with some binucleate cells. (H-E 200x). b. Close-up of the lesion. Note the mixed histiocytic infiltrate with isolated polynuclear infiltrates, and the irregularity of the vascular walls, which are mostly occluded (thick black arrow). (H-E x 200). c. Very close-up image of a thickened vessel wall with light stenosis and presence of large cells histiocytic in the neighboring region, with clear cytoplasm (thin black arrow). (H-E 400x) 


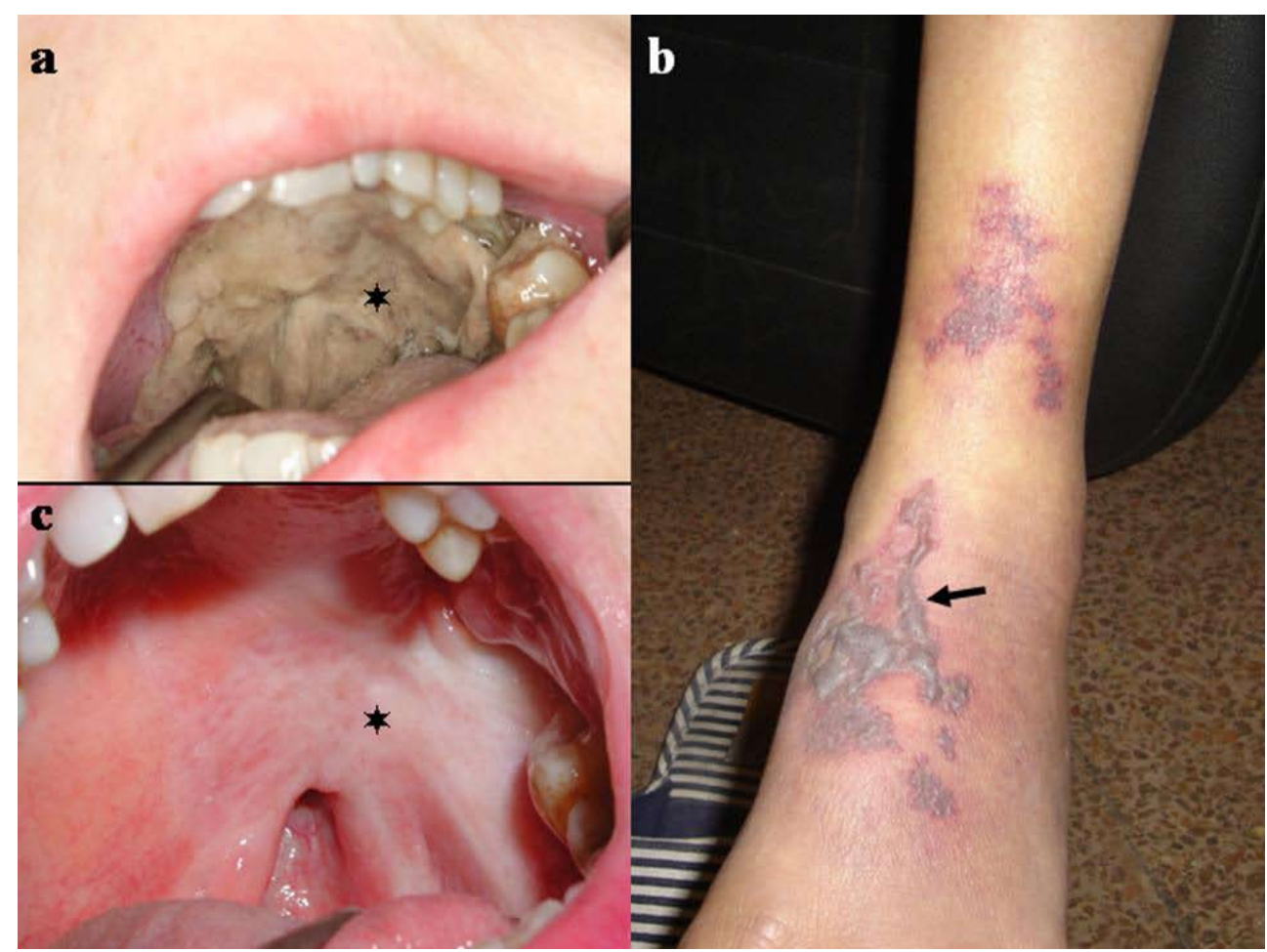

Fig. 2. a. Note the left palatal ulcer (asterisk). b. Palpable purpura on the lower part of the leg (arrow). c. 6 months after starting treatment, it can be observed that the areas shrink due to the scarring (asterisk).

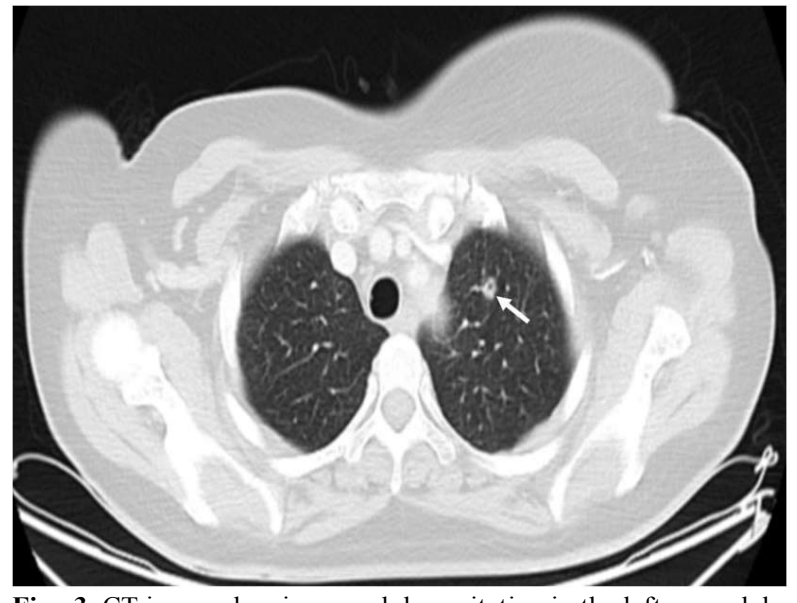

Fig. 3. CT image showing a nodule cavitation in the left upper lobe (white arrow).

$2 b)$. The biopsy of these lesions reported leukocytoblastic vasculitis with marked necrosis affecting the middle and deep dermis.

Given this clinical history, an analysis of the autoantibodies was requested, which revealed ANCA + (Antineutrophil Cytoplasmic Autoantibodies) with a cytoplasmic pattern (c-ANCA) and 181 antiproteasa 3 (PR3) antibodies. This, coupled with the anatomic pathological studies, resulted in the diagnosis of Wegener's disease.

An extension study was carried out, which consisted of a computerized tomography $(\mathrm{CT})$ of the chest and maxillofacial area, an erythrocyte sedimentation rate and an analysis of the urinary sediment. There was an increase in the inflammatory parameters in the blood. The thoracic $\mathrm{CT}$ revealed a $7.5 \mathrm{~mm}$ cavitated lump in the apical segment of the left upper lobe (Fig. 3); and the maxillofacial CT revealed inflammatory lesions in the cavum and in the oropharynx, with no bone lesion.

The urinary sediment presented a microscopic hematuria with 40/60 red blood cells per field, a proteinuria of $0.2 \mathrm{~g} / 24 \mathrm{~h}$, with the remaining kidney parameters within the normal range. The blood pressure readings were high (systolic blood pressure 170-140). A glomerulosclerosis was diagnosed due to focal and segmental necrosis.

As a preliminary treatment, a dose of $1 \mathrm{mg} / \mathrm{kg} /$ day of corticoid was presribed, observing a rapid clinical improvement of the arthralgia and of the analytical parameters. Maintenance therapy consisted of $50 \mathrm{mg} / 24 \mathrm{~h}$ prednisone for 1 year, associated with $50 \mathrm{mg} / 12 \mathrm{~h}$ cyclophosphamide for 6 months. For the renal impairment, ACE inhibitors (inhibitors of angiotensin-converting enzyme) and calcium channel blockers were added.

Within few weeks after starting the treatment, the ulcer began to epithelialize and 6 months after treatment, the oral ulcer had disappeared (Fig. 2c), and the patient was asymptomatic. In the one year follow-up, the patient remained free of disease. 


\section{Discussion}

The diagnosis of Wegener's granulomatosis is made by clinical features of illness associated with the presence of c-ANCA + and pathology (Table 1), characterized by a vasculitis of small arteries and veins, the presence of giant cells and epithelioid cell granulomas (2).

Table 1. Diagnostic criteria for Wegener's Granulomatosis according to The American College of Rheumatology (3). Two of the following four criteria must be met.

\begin{tabular}{|l|l|}
\hline \multicolumn{1}{|c|}{ Criteria } & \multicolumn{1}{c|}{ Definition } \\
\hline $\begin{array}{l}\text { Oral or nasal manifesta- } \\
\text { tion }\end{array}$ & $\begin{array}{l}\text { Oral ulcers or nasal secre- } \\
\text { tions }\end{array}$ \\
\hline $\begin{array}{l}\text { Alteration of lungs detect- } \\
\text { ed in x-ray or hemoptysis } \\
\text { during illness }\end{array}$ & $\begin{array}{l}\text { Infiltrating or cavitating no- } \\
\text { dules }\end{array}$ \\
\hline Urinary sediment & $\begin{array}{l}\text { Microhematuria: }>5 \text { erythro- } \\
\text { cytes per field }\end{array}$ \\
\hline Granulomatosis & $\begin{array}{l}\text { Inflammatory granulomatosis } \\
\text { in the arteries or small arter- } \\
\text { ies, affecting the perivascular } \\
\text { or extravascular wall }\end{array}$ \\
\hline
\end{tabular}

Although the c-ANCA are not considered a diagnostic criterion according to "The American College of Rheumatology", they have a $96 \%$ specificity and a $92 \%$ sensitivity (2). If the c-ANCA are negative, they do not necessarily exclude disease; in fact, in early stages, the analytical results of c-ANCA may be negative, especially if there is no renal involvement. In any case, they play an important role in the diagnosis and monitoring of the regression of the disease once treatment has been initiated (4).

Only $6 \%$ of patients with Wegener's granulomatosis present oral manifestations, however the majority appear during an advanced stage of the disease; oral symptoms are rarely an early indicator (4). Otorhinolaryngologic manifestations are more frequent during the course of the disease (5). Nasal involvement consists of rhinitis with a feeling of nasal obstruction, hemorrhagic or purulent nasal discharge and sinusitis. These nasal manifestations may be a predicting sign of disease activity and of relapse (2). Perforation of the nasal septum and saddle nose deformity may occur during the evolution, although it does not necessarily imply disease activity. The middle ear may experience a serous otitis due to inflammation of the Eustachian tube, or even a granulomatosis, affecting the middle ear. One-third of patients experienced a progressive sensorineural hearing loss within days or weeks, whose pathogenesis is unknown, and in most cases, the hearing loss persisted even after treatment of the disease. The oral lesions may be either mucosal ulcers on the tongue, jugal mucosa, gums or palate, or gingival hyperplasia with a "bruised" coloring. It may also manifest in the eyes, causing epiphora due to involvement of the nasolacrimal duct (6).

The diagnosis must be distinguished from among other granulomatous diseases such as Crohn's disease and sarcoidosis, granulomatous infections, midline NK/T-cell lymphomas and other ANCA + vasculitis (4), as well as microscopic polyangitis, which is a vasculitis that also affects small blood vessels and differs in histopathology due to the absence of granulomatosis $(7,8)$.

The case we presented meets the four criteria of the American College of Rheumatology (3) in order to be classified as Wegener's Disease (Table 1). These criteria include a biopsy with granulomatous inflammation affecting the mammary gland (chronic necrotizing mastitis), involvement of the oral mucosa (palate ulcers), presence of pulmonary nodule cavitation in the x-ray test, and abnormal urinary sediment with more than 5 erythrocytes/ field. In addition, hypertension and proteinuria, palpable purpura in the legs, oligoarthritis and presence of c-ANCA and PR3 serum were also present. It is essential to consider this disease when observing the presence of slowly evolving oral lesions such as those described, even though the c-ANCA are negative. The biopsies must be deep and must explore neighboring regions.

\section{References}

1. Burlacoff SG, Wong FS. Wegener's granulomatosis. The great masquerade: a clinical presentation and literature review. J Otolaryngol. 1993;22:94-105.

2. Sproson EL, Jones NS, Al-Deiri M, Lanyon P. Lessons learnt in the management of Wegener's Granulomatosis: long-term follow-up of 60 patients. Rhinology. 2007;45:63-7.

3. Leavitt RY, Fauci AS, Bloch DA, Michel BA, Hunder GG, Arend WP, et al. The American College of Rheumatology 1990 criteria for the classification of Wegener's granulomatosis. Arthritis Rheum. 1990;33:1101-7.

4. Eufinger H, Machtens E, Akuamoa-Boateng E. Oral manifestations of Wegener's granulomatosis. Review of the literature and report of a case. Int J Oral Maxillofac Surg. 1992;21:50-3.

5. Stewart C, Cohen D, Bhattacharyya I, Scheitler L, Riley S, Calamia K, et al. Oral manifestations of Wegener's granulomatosis: a report of three cases and a literature review. J Am Dent Assoc. 2007;138:338-48.

6. Rasmussen N. Management of the ear, nose, and throat manifestations of Wegener granulomatosis: an otorhinolaryngologist's perspective. Curr Opin Rheumatol. 2001;13:3-11.

7. Scardina GA, Fucà G, Carini F, Valenza V, Spicola M, Procaccianti $\mathrm{P}$, et al. Oral necrotizing microvasculitis in a patient affected by Kawasaki disease. Med Oral Patol Oral Cir Bucal. 2007;12:E560-4. 8. Eguia A, Villarroel M, Martínez-Conde R, Echebarría MA, Aguirre JM. Adamantiades-Behçet disease: an enigmatic process with oral manifestations. Med Oral Patol Oral Cir Bucal. 2006;11:E611 . 